\title{
Pembelajaran teks Ande-Ande Lumut dengan teknik sosiodrama di Escola Tecnica Informatica, Dili sebagai kegiatan ekstrkurikuler
}

\author{
Taufik Nugroho*) \\ PPPPTK Bahasa, Kementerian Pendidikan dan Kebudayaan \\ *) Corresponding author: Jalan Gardu RT.10 / RW.02, Srengseng Sawah, Jagakarsa, RT.10/RW.2, Srengseng Sawah, Kec. \\ Jagakarsa, Kota Jakarta Selatan, Daerah Khusus Ibukota Jakarta 12640, Indonesia; \\ e-mail: nugrahadouglassbrown@gmail.com
}

\begin{abstract}
Learning Indonesian language in Timor-Leste Vocational High Schools is intended to make students communicate Indonesian language effectively. Indonesian language as a foreign language as stipulated in Timor-Leste constitution plays a strategic role in education. Moreover, vocational education such as the Escola Tecnica Informatica (ETI), Dili, prepares graduates ready to work. Basic communication competencies are developed based on mastery of Indonesian language and literature. This paper aims to describe the results of the study of narrative text learning of Ande-Ande Lumut using sociodrama technique in class XI ETI, Dili as an extracurricular activity. The method used in this research is descriptive-qualitative method with case study technique. The research findings show that there are three benefits of integrating narrative text learning of Andeande Lumut with sociodrama technique, namely: (1) enhancing student attention through scenes; (2) make students understand psychosocial problems through the characters; and (3) make students emphathize to other people.
\end{abstract}

Key Words: Ande-ande lumut, narrative text, folklore, sociodrama.

c) (1) () This work is licensed under a Creative Commons Attribution-ShareAlike 4.0 International License

\section{Pendahuluan}

Pada hakikatnya pembelajaran bahasa merupakan proses yang bertujuan agar para pemelajar dapat berkomunikasi baik secara lisan maupun tulisan. Ada berbagai pendekatan, metode dan teknik pembelajaran bahasa yang dapat diterapkan agar pembelajaran bahasa efektif, efisien dan menarik sesuai dengan prioritas pembelajaran yang dituangkan dalam tujuan pembelajaran. Dalam bukunya yang berjudul Communicative Language Today (Richards, 2006) menguraikan tiga fase pendekatan penting dalam pembejaran/pengajaran bahasa, yakni: fase 1: Pendekatan Tradisional (Traditional Approaches) hingga tahun 1960-an; fase 2: Pendekatan Pengajaran Bahasa Komunikatif Klasik (Classic Communicative Language Teaching) mulai 1970-an hingga 1990-an; dan fase 3: Pengajaran Komunikatif Kontemporer (Current Communicative Language Teaching), dimulai akhir tahun 1990-an hingga sekarang.

Asumsi dari pendekatan tradisional memberikan prioritas pengajaran pada kompetensi gramatika (grammatical competence) yang merupakan basis keterampilan bahasa (language proficiency). Adapun metodologi yang tergolong pendekatan ini: Metode simak (Audiolingualism) di Amerika Utara dan Pendekatan Struktural-Situasional (the Structural-Situational Approach) di Inggris, juga dikenal dengan Pengajaran Bahasa Situasional (Situational Language Teaching). Teknik yang sering digunakan pada pendekatan ini termasuk menghafal dialog, praktik tanya jawab, substitusi latihan dan berbagai bentuk praktik berbicara dan menulis yang terbimbing. Pendekatan ini juga sangat memperhatikan pengucapan yang akurat dan penguasaan tata bahasa yang akurat ditekankan sejak tahap awal pembelajaran bahasa, sejak saat itu berasumsi bahwa jika siswa melakukan kesalahan ini dengan cepat akan menjadi bagian permanen dari kesalahan ucapan pelajar. Silabus yang digunakan pada fase ini merupakan daftar kata dan daftar gramatika berdasar jenjang (graded across levels).

Berbeda dengan pendekatan tradisional, pendekatan pengajaran bahasa komunikatif klasik mempertanyakan keefektifan pengajaran bahasa yang memprioritaskan pada pengajaran gramatika. Karena berbicara tentang kemampuan bahasa, lebih jauh dari sekedar penguasaan gramatika, yakni penguasaan 
54 Pembelajaran teks Ande-Ande Lumut dengan teknik sosiodrama di Escola Tecnica Informatica, Dili sebagai kegiatan ekstrkurikuler

kompetensi komunikatif (communicative competence). Kompetensi gramatikal diperlukan untuk menghasilkan kalimat yang benar secara tata bahasa. Kemudian, perhatian bergeser dari kompetensi gramatika ke pengetahuan dan keterampilan yang dibutuhkan untuk menggunakan tata bahasa dan aspek bahasa lainnya secara tepat untuk tujuan komunikatif yang berbeda, seperti membuat permintaan, memberi saran, membuat saran, menggambarkan keinginan dan kebutuhan dan sebagainya. Apa yang dibutuhkan untuk menggunakan bahasa secara komunikatif adalah kompetensi komunikatif.

Silabus yang digunakan pada pendekatan ini: 1). silabus berbasis keterampilan ini (skill-based syllabus) berfokus pada empat keterampilan membaca, menulis, mendengarkan, dan berbicara, dan komponen-komponen mikronya: keterampilan mendengarkan mungkin dijelaskan lebih lanjut dalam ketentuan dari microskills berikut: mengenali kata-kata kunci dalam percakapan, topik pembicaraan, sikap pembicara terhadap suatu topik, referensi waktu dari ucapan, dan lain-lain; dan 2). silabus fungsional: ini disusun sesuai dengan fungsi yang harus dapat dilakukan oleh pemelajar ahasa Inggris, seperti mengekspresikan suka dan tidak suka, menawarkan dan menerima permintaan maaf, memperkenalkan seseorang, dan member penjelasan. Kompetensi komunikatif dipandang sebagai penguasaan fungsi yang dibutuhkan untuk komunikasi di berbagai situasi.

Menyempurnakan pendekatan pengajaran bahasa komunikatif klasik yang menekankan kompetensi komunikatif secara terbatas, pendekatan Pengajaran Bahasa Komunikatif Terkini (Current CLT) mengacu pada tradisi sebelumnya dalam pengajaran bahasa komunikatif dan berlanjut untuk membuat referensi sampai batas tertentu dengan pendekatan tradisional. Jadi kegiatan kelas biasanya memiliki beberapa dari karakteristik berikut: 1). mengembangkan kompetensi komunikatif siswa melalui menghubungkan pengembangan tata bahasa untuk kemampuan berkomunikasi. Karenanya tata bahasa tidak diajarkan secara terpisah tetapi sering muncul dari bagian tugas komunikatif; 2). menciptakan kebutuhan akan komunikasi, interaksi, dan negosiasi makna melalui kegiatan seperti pemecahan masalah, berbagi informasi, dan bermain peran; 3). memberikan peluang untuk pembelajaran tata bahasa induktif maupun deduktif; 4). memanfaatkan konten yang menghubungkan kehidupan dan minat siswa; 5). memungkinkan siswa mempersonalisasikan pembelajaran dengan menerapkan apa yang telah mereka pelajari dalam kehidupan mereka sendiri; dan 6). bahan-bahan pelajaran biasanya menggunakan teks-teks otentik untuk menciptakan minat dan untuk memberikan valid model bahasa.

Silabus bahasa pada pendekatan ini perlu menyertakan cakupan sistematis berbagai komponen komunikatif yang berbeda kompetensi, termasuk keterampilan bahasa, konten, tata bahasa, kosakata, dan fungsi. Jenis silabus yang berbeda dalam orientasi komunikatif untuk pengajaran bahasa menggunakan rute yang berbeda untuk berkembang kompetensi komunikatif.

Adapun beberapa metodologi yang termasuk Pengajaran Bahasa Komunikatif Terkini (Current CLT) atau pendekatan komunikatif yang diperluas, yakni: (1). Pendekatan berbasis proses (process-based CLT approaches): pengajaran berbasis isi (content based instruction) dan pengajaran berbasis tugas (taskbased instruction); (2). Pendekatan Berbasis Produk (Product-based CLT approaches): Pengajaran Berbasis Teks (text-based instruction) dan Pengajaran Berbasis Kompetensi (competency-based instruction).

Berdasarkan uraian fase-fase pendekatan pembelajaran di atas, penulis memilih pendekatan berbasis produk, yakni pengajaran berbasis teks. Pendekatan tersebut sangat relevan dengan topik yang dibahas dalam penelitian, yakni pembelajaran teks naratif cerita rakyat, yang memuat langkah-langkah: membangun pengetahuan konteks (building knowledge of the field); pemodelan teks (modeling of the text); membuat teks berkelompok (joint consctruction of the text); dan membuat teks mandiri (independent construction of the text).

Proses Pembelajaran pada satuan pendidikan diselenggarakan secara interaktif, inspiratif, menyenangkan, menantang, memotivasi peserta didik untuk berpartisipasi aktif, serta memberikan ruang yang cukup bagi prakarsa, kreativitas, dan kemandirian sesuai dengan bakat, minat, dan perkembangan fisik serta psikologis peserta didik. Untuk itu setiap satuan pendidikan melakukan perencanaan pembelajaran, pelaksanaan proses pembelajaran serta penilaian proses pembelajaran untuk meningkatkan efisiensi dan efektivitas ketercapaian kompetensi lulusan.

Pada kesempatan ini sesuai dengan fokus penelitian ini, akan dipaparkan pengintegrasian pembelajaran teks naratif cerita rakyat Ande-ande Lumut melalui metode sosiodrama untuk menghayati nilai-nilai budaya yang terkandung di dalamnya. 


\section{Metode}

Pendekatan penelitian yang digunakan deskriptif-kualitatif dengan metode studi kasus yang merupakan suatu serangkaian kegiatan ilmiah yang dilakukan secara intensif, terinci dan mendalam tentang suatu program, peristiwa, dan aktivitas, baik pada tingkat perorangan, sekelompok orang, lembaga, atau organisasi untuk memperoleh pengetahuan mendalam tentang peristiwa tersebut. Biasanya, peristiwa yang dipilih yang selanjutnya disebut kasus adalah hal yang aktual (real-life events), yang sedang berlangsung, bukan sesuatu yang sudah lewat (Rahardjo, 2017).

Studi ini dilakukan dalam latar alamiah, holistik dan mendalam. Alamiah artinya kegiatan pemerolehan data dilakukan dalam konteks kehidupan nyata (real-life events). Tidak perlu ada perlakuanperlakuan tertentu baik terhadap subjek penelitian maupun konteks di mana penelitian dilakukan. Biarkan semuanya berlangsung secara alamiah. Studi ini dilaksanakan di Escola Tecnica Informatika kelas XI C pada bulan Mei 2019.

\section{Pembahasan}

Pada bagian ini akan diuraikan dan dibahas yang merupakan hasil temuan penelitian yang merupakan implementasi dari pengintegrasian pembelajaran berbasis teks naratif dengan teknik sosiodrama pada siswa kelas XI C Escola Tecnica Informatika, Dili, Timor-Leste. Perlu diketahui pula bahwa pelaksanaan pembelajaran ini, yang sekaligus merupakan pelaksanaan penelitian dilakukan di luar pembelajaran di kelas atau kegiatan ekstra kurikuler. Hal ini dimaksudkan agar peneliti memiliki waktu yang cukup untuk menyelesaikan penelitiannya. Sebagai informasi tambahan bahwa pembelajaran bahasa Indonesia di sekolah-sekolah Timor-Leste, mulai dari Sekolah Dasar sampai dengan Sekolah Menengah Atas/Kejuruan diajarkan hanya satu jam pelajaran (1 X 45 menit) per minggu, dan sebagian besar di sekolah-sekolah swasta. Sedangkan, di Perguruan Tinggi pada umumnya mata kuliah bahasa Indonesia diajarkan dalam durasi 2 SKS (2 X 50 menit).

Berikut disajikan tahapan pembelajaran yang merupakan pengintegrasian pembelajaran berbasis teks naratif Ande-ande Lumut dengan teknik sosiodrama:

\section{A. Tahap I}

\section{Mengenal Teks Cerita Rakyat Ande-Ande Lumut Pertemuan 1 (2 X 45 minutes)}

\section{1) Pendahuluan}

a. Pra-aktivitas pembelajaran: apersepsi

b. Peserta didik merespon salam tanda mensyukuri anugerah Tuhan dan berdoa.

c. Peserta didik merespon pertanyaan dari guru berhubungan dengan pembelajaran sebelumnya.

d. Peserta didik menerima informasi dengan proaktif tentang keterkaitan pembelajaran sebelumnya dengan pembelajaran yang akan dilaksanakan.

e. Peserta didik menerima informasi tentang hal-hal yang akan dipelajari dan dikuasai khususnya tentang pembelajaran cerita rakyat.

\section{2) Aktivitas Utama}

a. Membangun Pengetahuan Konteks (Building Knowledge of the Field)

Aktivitas 1: (1) Tonton dan simaklah video musik Ande-Ande Lumut yang diperdengarkan dan ditayangkan oleh guru; (2) Perhatikan dialog yang yang terdapat pada video tersebut. Guru dan siswa bersama-sama menyimak ungkapan-ungkapan dalam video tersebut, dan bila perlu menterjemahkan lirik lagu tersebut ke dalam bahasa Indonesia; (3) Menyanyikan bersama lagu tersebut seperti yang ada di video.

Aktivitas 2: Bacalah bahan bacaan berikut. Identifikasi fungsi sosial, struktur teks, dan fitur kebahasaanya. 


\begin{abstract}
ANDE-ANDE LUMUT
Ande Ande Lumut adalah cerita rakyat yang berasal dari Jawa. Cerita ini dikenal dalam berbagai versi. Versi yang banyak dikenal dan "tradisional" adalah yang mengaitkannya dengan bersatunya (kembali) Kerajaan Jenggala dan Kediri.

Cerita ini mengisahkan tentang Pangeran Kusumayuda (dianggap sebagai personifikasi Kamesywara, raja Kadiri) yang bertemu dengan Kleting Kuning (bahasa Jawa: Klething Kuning), si bungsu dari empat bersaudara anak seorang janda yang tinggal di salah satu desa bawahan ayah Pangeran Kusumayuda memerintah. Kleting Kuning sebenarnya adalah anak angkat, yaitu putri dari Kerajaan Jenggala, yang kelak dikenal sebagai Dewi Candrakirana. Diam-diam mereka saling mengingat. Dalam hati, Pangeran Kusumayuda tahu, gadis seharum bunga mawar itu adalah calon permaisuri Kerajaan Banyuarum yang paling sempurna. Sayang, mereka tak pernah bertemu lagi.

Beberapa tahun kemudian, seorang pemuda tampan bernama Ande Ande Lumut mengumumkan bahwa dia sedang mencari istri. Tak seperti gadis-gadis desa lain, termasuk juga saudara-saudara Kleting Kuning, Kleting Kuning enggan pergi sebab dia masih mengingat Pangeran Kusumayuda. Namun berkat nasihat dari bangau ajaib penolongnya, maka akhirnya Kleting Kuning pun turut serta.

Dalam perjalanannya, ternyata mereka harus menyeberangi sungai yang lebar. Pada saat itu, muncullah penjaga sungai berwujud yuyu raksasa bernama Yuyu Kangkang. Yuyu Kangkang menawarkan jasa untuk menyeberangkan mereka dengan catatan diberi imbalan bersedia dicium olehnya setelah diseberangkan. Karena terburu-terburu, semua gadis-gadis desa yang lain segera saja menyetujuinya, dengan pemikiran bahwa sang pangeran tidak akan mengetahuinya. Hanya si bungsu Kleting Kuning yang menolak untuk dicium Yuyu Kangkang. Ketika Yuyu Kangkang bermaksud memangsanya, Kleting Kuning melawannya dengan senjata yang dititipkan oleh ibunya. Karena hanya si bungsu yang tidak dicium Yuyu Kangkang, jadilah Ande Ande Lumut memilih si bungsu sebagai pendampingnya. Barulah saat itu Kleting Kuning menyadari bahwa pemuda Ande Ande Lumut adalah Pangeran Kusumayuda, pemuda idamannya.
\end{abstract}

b. Pemodelan teks (Modeling of the Text):

1) Guru membimbing para peserta didik menanyakan tema teks Ande-ande Lumut.

2) Guru membimbing para peserta didik menanyakan struktur teks cerita tersebut.

- Pada tahap orientasi dapat ditanyakan kapan, di mana, siapa tokoh-tokoh yang terlibat, siapa tokoh utamanya, dan sifat/karakteristik setiap tokoh

- Pada tahap konflik dapat ditanyakan konflik apa yang terjadi pada cerita tersebut; siapa tokoh-tokoh yang berkonflik, siapa tokoh-tokoh yang terlibat; pada bagian mana klimaks (puncak konflik).

- Pada tahap resolusi dapat ditanyakan pada bagian mana dalam cerita yang menunjukkan selesaian.

3) Guru membimbing para peserta didik menanyakan fitur kebahasaan teks Ande-Ande Lumut.

- keterangan waktu apa saja yang sering digunakan pada jenis teks ini.

- tatabahasa yang sering digunakan

- gaya bahasa apa saja yang dipakai

- dialek apa saja yang muncul

4) Nilai budaya/ pesan moral budaya apa yang dapat dipetik dari teks Ande-Ande Lumut

c. Membuat teks berkelompok (Joint Consctruction of the Text)

1) Secara berkelompok, carilah teks cerita rakyat Ande-Ande Lumut selain contoh di atas atau versi lain bisa berbentuk video baik klasik maupun modern, ketoprak, atau bentuk animasi.

2) Identifikasi fungsi sosial, struktur teks, dan fitur kebahasaan dari versi cerita Ande-Ande Lumut yang ditemukan. 


\section{B. Tahap II}

\section{Mengenal Teks Cerita Rakyat Ande-Ande Lumut Pertemuan 2 (2 X 45 minutes)}

\section{1) Pendahuluan}

a. Pra-aktivitas pembelajaran: apersepsi

b. Peserta didik merespon salam tanda mensyukuri anugerah Tuhan dan berdoa.

c. Peserta didik merespon pertanyaan dari guru berhubungan dengan pembelajaran sebelumnya.

d. Peserta didik menerima informasi dengan proaktif tentang keterkaitan pembelajaran sebelumnya dengan pembelajaran yang akan dilaksanakan.

e. Peserta didik menerima informasi tentang hal-hal yang akan dipelajari dan dikuasai khususnya tentang pembelajaran cerita rakyat.

2) Aktivitas Utama:

a. Membuat teks berkelompok (joint consctruction of the text) dan membuat teks mandiri (independent construction of the text)

(1) Mengubah informasi tentang teks Ande-Ande Lumut yang didapat selama pembelajaran sebelumnya dengan menstranfer ke bentuk naskah skenario drama.

\section{Naskah Drama Ande Ande Lumut}

Di Sebuah Desa, yaitu Desa Dadapan ada seorang wanita tua yakni Mbok Randa Dadapan yang memiliki anak bernama Ande Ande Lumut.Dia adalah pemuda yang sangat tampan, gagah dan menjadi dambaan para wanita. Sebenarnya Ande Ande lumut bukanlah anak kandung Mbok Randa melainkan hanya anak asuh.

Di desa lain, yaitu Desa Jenggala, ada seorang wanita yang sangat cantik yang tinggal bersama ibu tirinya dan dua saudara tirinya yg bernama Klinting Merah dan Klinting Biru.Wanita tersebut bernama Klinting Kuning.Sayangnya Klinting Kuning diperbudak dan dicaci maki oleh ibu dan saudara tirinya.Suatu hari :

Klinting Merah : :'Kuning,cepat bawakan masakanmu kami sudah tak tahan Menahan lapar" (nada membentak)

Klinting Kuning

Klinting Biru

Klinting Kuning $\mathrm{Ibu}$

:"Iya kakak kuning datang"(sambil membawa makanan)

:"Cuma masak gini aja lama banget!!dasar gak becus!!"

:"Maaf kak"

:"Sudah sudah,kamu itu memang gk becus kuning!!setelah ini km

Harus menananam bunga di halaman luar!!"

Klinting Kuning

:"Baik bu"

(Ditempat lain)

Mbok Randa

:"Anakku kau sudah besar,sudah waktunya untuk menikah,carilah Pendamping hidupmu"

Ande ande lumut : :'Iya bu,sebenarnya aku sudah mempunyai dambaan hati,namun Aku belum tau pasti siapa dirinya"

Mbok Randa

:"Hmm...Bagaimana kalau ibu membuat acara ande ande lumut Mencari dambaan hati?semacam take me out gitu?"

Ande ande lumut : :Baiklah bu aku setuju"

Saat Klinting Kuning menanam bunga ada pembawa berita yang berteriak teriak.

Pembawa Berita :'Pengumuman pengumuman...ada jejaka yang sedang mencari Wanita dambaannya...yang berminat harap ke rumah ande ande Lumut besok pagi"

Klinting Kuning :"Eh...pak pak,dimanakah rumah si Ande ande lumut?"

Pembawa Berita : :'Loh?neng tidak tau ya?rumah Ande ande lumut sudah diketahui Banyak masyarakat terutama kaum hawa" 


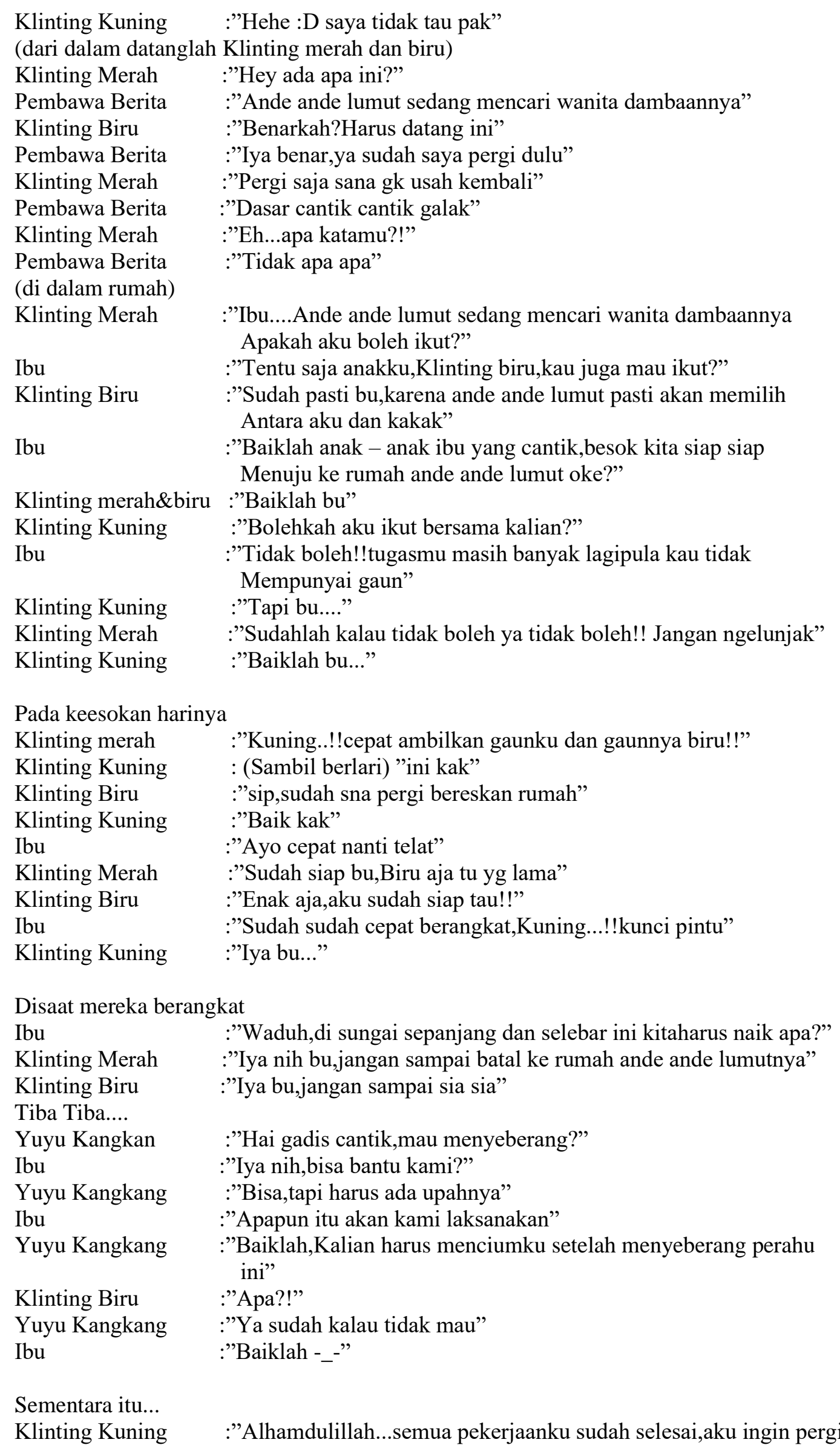


Ke rumah Ande ande lumut sekarang"

Di sungai Yuyu Kangkang

Klinting Kuning :'Haduh...gimana ini?aku tidak mungkin menyeberang tanpa alat Apapun"

Yuyu Kangkang

Klinting Kuning

Yuyu Kangkang

Klinting Kuning

:"Hai...apakah kau ingin menyeberang?"

:"Iya bolehkah aku menumpang?"

:"Baiklah boleh saja,kau tak usah bayar juga gak papa kok"

:"Terima Kasih Yuyu Kangkang"

Di lain tempat....

Klinting Merah,Klinting biru,dan ibunya datang ke rumah Ande ande lumut

Mbok Randa : :'Siapakah kalian wahai gadis gadis cantik?"

Ibu

:"Saya mengantar kedua putri saya untuk bertemu dengan Ande Lumut,bisakah kami bertemu?'

Mbok Randa :"Oh tentu saja,Putraku....keluarlah ada dua gadis ingin bertemu"

Ande Ande Lumut :'Iya bu"

Mbok Randa : :"Inikah wanita yang kau cari putraku?"

Ande Ande Lumut : :'Bukan bu,aku tidak sudi menjalin hubungan dengan gadis yang

Sudah menjadi korban Yuyu Kangkang seperti mereka"

(lalu masuk ke dalam rumah)

Ibu :"Kurang ajar kau menghina anakku seperti itu"

Mbok Randa : :Maafkan anak saya,memang begitulah resikonya"

Ibu :'Baiklah kalau begitu"

Tiba tiba Klinting Kuning datang

Klinting biru

$\mathrm{Ibu}$

Klinting Kuning

Mbok Randa

Klinting Kuning

Mbok randa

Klinting Kuning

Mbok Randa

Ande ande lumut

Mbok Randa

Ande ande lumut

Klinting Kuning

Ande ande lumut

Klinting Kuning
:"Klinting Kuning?!"

:"Bagaimana kau bisa datang?apakah tugas rumah sudah berhasil Kau selesaikan?"

:"Sudah bu"

:"Ada apa gadis cantik?Apakah kau ingin bertemu dengan Putraku?"

:"'Iya bu,bolehkah saya bertemu dg Ande ande lumut?"

:"Tentu saja,tapi apakah kau siap ditolak oleh putraku?"

:"Saya akan terima apapun keputusannya"

:"Baiklah...Ande ande lumut,ada gadis cantik ingin bertemu Denganmu"

:"Iya bu..."

:"Apakah ini wanita yang kau cari cari?"

:'Iya bu,siapakah namamu wahai gadis cantik?"

: "Saya adalah Klinting Kuning tuan"

:"Kau sangat cantik,aku sudah mengerti sifatmu wahai gadis Maukah kau menjadi pendamping hidupku?"

:'Tentu saja tuan"

(Lalu bergandengan tangan)

Setelah kejadian tersebut Ande ande lumut dan Klinting Kuning menjadi keluarga yang bahagia.Sedangkan,Ibu dan saudara tiri Klinting Kuning hidup sengsara karena kejahatan yang telah diperbuat oleh mereka selama ini. TAMAT

(2) Pada kegiatan ini digunakan metode sosiodrama dengan langkah-langkah berikut:

(a) Guru memberikan pengarahan kepada seluruh peserta didik sebelum bermain peran. Peserta didik dibagi ke dalam beberapa kelompok untuk bermain peran sesuai dengan 
skenario tokoh dan penokohan (karakteristik) yang dibuatnya. Menentukan siapa menjadi siapa, misalnya:

Siswa 1: Ande-Ande Lumut: tegas, setia, cerdas, tampan

Siswa 2: Nyai Intan: keras, oportunis, avonturir

Siswa 3: Mbok Rondo: bijak, arif, setia

Siswa 4: Klenting Abang: cantik, lincah, menghalalkan segala cara

Siswa 5: Klenting Ijo: cantik, komprimistis, pragmatis

Siswa 6: Klenting Biru: cantik, judes, avonturir, licik

Siswa 7: Klenting Kuning: setia, sederhana, jujur, pemberani, rendah hati

Siswa 8: Yuyu Kang Kang: licik, aji mumpung, menghalalkan segala cara, kasar

(b) Guru menjelaskan secara rinci ihwal tema, alur, tokoh, dan penokohan yang arus menjadi acuan bagi setiap kelompok harus memilih masalah yang urgen, sehingga menarik minat anak. Ia mampu menjelaskan dengan menarik sehingga siswa terangsang untuk berusaha memecahkan masalah itu.

(c) Agar siswa memahami peristiwanya, maka guru harus bisa meneceritakan sambil untuk mengatur dengan adegan yang pertama (pemodelan).

(d) Bila ada kesediaan sukarela dari siswa untuk berperan, harap ditanggapi tetapi guru harus mempertimbangkan apakah ia tepat untuk perannya. Bila tidak ditunjuk saja siswa yang memiliki kemampuan dan pengetahuan serta pengalaman seperti yang diperankan itu.

(e) Jelaskan pada pemeran-pemeran itu sebaik-baiknya sehingga mereka tahu tugas perannya, menguasai masalahnya, pandai bermimik maupun berdialog.

(f) Siswa yang tidak turut tampil (kelompok lain) menjadi penonton yang aktif, di samping mendengarkan dan melihat mereka harus bisa memberi saran dan kritik pada apa yang akan dilakukan setelah sosiodrama selesai.

(g) Bila siswa belum terbiasa perlu dibantu guru dalam menimbulkan kalimat pertama dalam dialog.

(h) Setelah dalam situasi klimaks, maka harus dihentikan agar kemungkinankemungkinan pemecahan masalah dapat didiskusikan secara umum. Sehingga para penonton ada kesempatan untuk berpendapat, menilai permainan, dan sebagainya. Sosiodrama dapat dihentikan pula bila sedang menemui jalan buntu.

(i) Sebagai tindak lanjut dari hasil diskusi walau mungkin masalahnya belum terpecahkan, maka perlu dibuka tanya jawab, diskusi atau membuat karangan yang berbentuk sandiwara/drama serupa.

\section{b. Membuat teks berkelompok (joint consctruction of the text) dan membuat teks mandiri (independent construction of the text)}

(1) Setiap kelompok menampilkan drama Ande-Ande Lumut sesuai dengan skenario dan arahan sutradara kelompok masing-masing.

(2) Kelompok lain mengamati penampilan kelompok yang lainnya untuk mencatat hal-hal penting dan unik dalam adegan-adegan yang ditampilkan sebagai bahan diskusi.

\section{Simpulan}

Dari uraian di atas, dapat disimpulkan bahwa pengintegrasian pembelajaran cerita rakyat Andeande Lumut dengan metode sosiodrama dapat diimplementasikan sesuai dengan apa yang ditentukan dalam pencapaian kompetensi dasar mata pelajaran bahasa Indonesia. Sebagaimana diketahui bersama, pembelajaran abad ke-21 menekankan pada pendekatan berbasis aktivitas yang menjadi target karakter peserta didik adalah berpikir kritis dan pemecahan masalah (critical thinking and problem solving), kreatif dan inovatif (creative and innovative), kemampuan berkomunikasi (communication skill), kemampuan bekerja sama (collaboration) dan kepercayaan diri (confidence).

Pengintegrasian pembelajaran berbasis teks naratif cerita rakyat Ande-ande Lumut dengan metode sosiodrama setidaknya mendatangkan tiga manfaat, yakni: 1). mempertinggi perhatian siswa melalui adegan-adegan; 2). membuat siswa mengerti persoalan sosial psikologis dan ikut merasakan perasaan dan 
pikiran orang lain; dan 3). membuat siswa dapat menempatkan diri pada tempat orang lain (empati) dan memperdalam pengertian mereka tentang orang lain.

Pengintegrasian pembelajaran teks naratif cerita rakyat Ande-ande Lumut dengan metode sosiodrama dapat menstimulasi siswa-siswi berpikir kreatif dan inovatif mulai dari proses mengkonversi teks naratif asli menjadi skenario drama, memilih tokoh-tokoh, berekspresi sesuai dengan perwatakan tokoh, dan akhirnya menampilkan drama tersebut. Kedua teknik ini sangat relevan dengan pembelajaran abad ke-21 yang mensyaratkan karakter kreatif, inovatif, komunikatif dan kolaboratif.

\section{Ucapan Terima Kasih}

Terima kasih penulis ucapkan kepada tim editor Jurnal Bahasa Indonesia bagi Penutur Asing (JBIPA) sehingga artikel penelitian ini dapat diterbitkan di jurnal ini.

\section{Daftar Rujukan}

Departemen Pendidikan Nasional. Pusat Bahasa. (2007). Kalarahu: Kumpulan Cerita Rakyat Jawa. Jakarta: Pusat Bahasa.

Fariqotul, Ika. Christian University of Indonesia, Swasta, https://www.academia.edu/8499260/Andeande_lumut

Poerwadarminta, W.J.S. 2002. Kamus Umum Bahasa Indonesia, Jakarta: Balai Pustaka.

Purbani, Arti. 2011. Ande-Ande Lumut. Jakarta: Balai Pustaka.

Rahardjo, M. (2017). Studi kasus dalam penelitian kualitatif: konsep dan prosedurnya.

Richards, J. C. (2006). Communicative Language Teaching Today. Retrieved from www.cambridge.org

Sanjaya, H. Wina. (2012). Strategi Pembelajaran Berorientasi Standar Proses Pendidikan. Jakarta: Kencana Prenada Media Group.

Syah, Muhibbin. (2002). Psikologi Pendidikan dengan Pendekatan Baru. Bandung: PT. Remaja Rosdakarya. 